\title{
SAN JOSÉ EN LA SAGRADA ESCRITURA Y EN LA ESPIRITUALIDAD
}

\author{
Saint Joseph in Sacred Scripture and in Spirituality \\ Wilma Mancuello González ${ }^{\mathrm{I}}$ \\ Carlos Alberto Medina Cristaldo ${ }^{2}$
}

\section{Resumen}

El artículo estudia, desde la exégesis bíblica y la espiritualidad cristiana católica, la figura de san José. Busca releer algunos rasgos de su persona y sugerir respuestas a los interrogantes acerca del trato que el Señor Dios le dispensa y su modo de responder a la llamada divina. La espiritualidad cristiana ha subrayado, siempre, su silencio como expresión de su profunda obediencia a los planes de Dios y le ha adjudicado muchos epítetos: padre putativo de Jesús, custodio y esposo de María, patrono de los obreros, patrono de las vocaciones, etc. Nuestra investigación, basada en textos evangélicos y veterotestamentarios analizados conforme a la naturaleza de los textos con herramientas propias de los métodos sincrónicos, propone comprender el trato dispensado por Dios a José y su modo de corresponderle a causa de su profunda amistad con Él al estilo de Abraham y de los profetas bíblicos: Oseas, Jeremías y Ezequiel. Lo presenta, también, a modo de relectura actualizante, como un hombre contemplativo de los misterios del Reino, el maestro de Jesús y diligente protector de los indefensos de la historia. Y en esta línea, el estudio encuentra en la espiritualidad un enlace lejano, cargado de fuerza renovadora, en la relación de amistad que tuvo con san José, la primera doctora de la iglesia católica, denominada "maestra de oración": Teresa de Jesús. Ella, a su vez, invita a los cristianos escoger a San José como maestro de oración, aficionársele para aprender a tratar de amistad con quien sabemos nos ama.

Palabras clave: Evangelios; Espiritualidad; San José; Teresa de Jesús; Amistad; Profetas; Carpintero; Maestro; Padre; Oración; Sagrada Escritura.

1 Doctora en Sagradas Escrituras por el Pontificio Instituto Bíblico de Roma, Italia. Máster en Antropología Social por la Facultad de Filosofía y Ciencias Humanas de la Universidad Católica Nuestra Señora de la Asunción, Paraguay. Religiosa de la congregación de las Misioneras de la Institución Claretiana y docente de la Facultades de la Sagrada Teología y de Ciencias Humanas de la Universidad Católica Nuestra Señora de la Asunción. Correo electrónico: wilmancuello23@ gmail.com

2 Licenciado en Teología Espiritual por la Facultad de Teología del Norte de España, Burgos, España. Religioso de la Orden de los Carmelitas Descalzos. Correo electrónico: albertocrstld4@gmail.com 


\section{Abstract}

The article addresses the figure of Saint Joseph from the point of view of biblical exegesis and Catholic spirituality. It aims at reinterpreting some features of his character and suggests some answers concerning how God interacted with him and his form of answering the divine call. Christian spirituality has always interpreted his silence as an expression of his profound obedience and has granted him with several epithets: Putative or Nominal Father of Jesus, Guardian of the Redeemer, Husband of Mary, Patron Saint of Carpenters, among others. The research is based on texts of both the Old and New Testaments, which are studied according to their own nature and using analytic tools of the synchronic approach. Its purpose is to understand how God handled Joseph and the way in which he answered his call, which was based on a profound friendship with God Himself, just like Abraham and some biblical prophets. He is also represented, as a form of re-reading, as a contemplative man of the mysteries of the Kingdom, as the master of Jesus, and diligent protector of those in need throughout history. In this line of argument, the research finds a distant spiritual link, though bearing upgrading force, in the friendship Saint Joseph had with Teresa of Jesus, first female Doctor of the Church and regarded as Doctor of Prayer. She invites Christians to choose Saint Joseph as Master of Prayer, following him to learn of friendly conversation with Him Who we know loves us.

Keywords: Gospels; Spirituality; Saint Joseph; Teresa of Jesus; Friendship; Prophets; Carpenter; Teacher; Father; Prayer; Holy Scripture.

\section{Introducción}

Las raíces bíblicas del aprecio del cristianismo por la figura de José se encuentran en los dos primeros capítulos de los evangelios de Mateo y Lucas ${ }^{3}$, es decir, los relatos de la infancia de Jesús ${ }^{4}$. Los textos de Mt 1,18-25; 2,13-15 y19-23 narran cómo Dios interviene en los planes de José y cómo él, inmediatamente, responde al Señor, sin emitir protesta alguna ni expresar preguntas. Ha prevalecido en el cristianismo la figura de José como hombre de profundo y absoluto silencio. Se ha explicado este modo de actuar con base en las categorías de obediencia y disponibilidad ante la iniciativa divina y, muy recientemente, como "signo de su importancia en relación a la figura y misión de Jesús" (Pedroli, 2019, p. 64). ¿Cabrían otras intepretaciones tanto desde la exégesis bíblica como desde la teología espiritual?, ¿por qué Dios pide a José acometer semejante empresa sin darle la oportunidad de presentar sus dudas verbalmente como María, según Lc 1,34?, ¿por qué le trata así?, y ¿a qué se debe que José responda al llamado divino sin titubeos ni protesta alguna?, ¿podría hallarse otro papel de San José en la espiritualidad y para la espiritualidad de hoy? Tales son los interrogantes que guían nuestro estudio, a los que busco, fundamentalmente, dar respuesta, con el fin de contrarrestar -con tantos otros autores- la influencia negativa que han jugado los apócrifos sobre la figura de San José en la tradición católica (Carrasco, 1993, pp. 29-45).

3 Los textos provienen de la edición crítica de Aland, K., et al. (Eds.). (1993). Novum Testamentum Graece. Stuttgart: Deutsche Bibelgesellschaft.

4 Para un estudio reciente sobre el ambiente socio-cultural de los relatos de la infancia de Jesús, véase: Sacchi, A. (2018).

"Un bambino è nato per noi”. La nascita di Gesù secondo Matteo e Luca. (pp. 13-39). Milano: Youcanprint Self-Publisching. 
El estudio es de estructura bipartita. La primera aborda la figura de José, tal como aparece en la Sagrada Escritura, y ofrece una relectura de la misma sobre la base de los textos vétero y neotestamentarios. Se focaliza en la relación de José con Jesús, la influencia que tuvo en su vida, además de describir su rol de padre y de docente, según la tradición sapiencial, su vocación al cuidado, a la defensa y protección de los indefensos de la historia. Además, se propone su amistad con Dios como clave de lectura del trato que recibe de Dios quien, de improviso, se ve obligado a cambiar su proyecto de vida. Se sugiere que, detrás de la presentación evangélica de José, podría identificarse al patriarca Abraham y a algunos profetas del Antiguo Testamento.

En la segunda parte se rastrea, dentro de una espiritualidad cristiana específica de larga trayectoria y de influjo en la vida de la Iglesia universal, elementos que puedan iluminar la precedente propuesta de interpretación bíblica de la persona de San José. Se recurre a Teresa de Jesús, la primera mujer proclamada como doctora de la Iglesia católica y maestra de oración. Primeramente, se ofrece una pincelada sobre la espiritualidad cristiana, después se ubica en la historia personal de la santa el momento inicial de contacto con San José y posteriormente se delinea su proceso de amistad para luego, finalmente, presentar la invitación de Teresa al mundo cristiano: escoger a San José como maestro de oración. Es decir, como hábil pedagogo en la relación de amistad y de intimidad con Dios.

\section{José en la tradición bíblica y su influencia en la vida de Jesús}

\section{La relación padre e hijo en la tradición religiosa de Jesús}

En el Antiguo Testamento, los hijos son la bendición más preciada de Dios a los padres (Sal 128,1-4; 127,35). Ellos garantizan la continuidad del progenitor $\left(\operatorname{Sir}^{5} 30,4\right)$ y la perennidad de su nombre (Sir 40,19; Sal 144,12a; Rut 4,14). En cambio, si desaparecen los hijos, desaparece la memoria. En esta concepción, la familia está abierta al mundo circundante. Los padres, además de proteger a sus propios hijos, nietos y parientes cercanos, extienden sus brazos a los desamparados de la sociedad: los pobres, los huérfanos, las viudas. Así, la madre y esposa de Pr 31,10-31 es alabada y felicitada por su marido e hijos (v. 28), entre otras cosas, porque "extiende su palma al desvalido y tiende su mano al pobre" (v. 20). Job, padre de muchos hijos e hijas $(1,2 ; 42,13)$, recuerda sus días felices diciendo: "Yo libraba al pobre que pedía auxilio y al huérfano indefenso, recibía la bendición del vagabundo y alegraba el corazón de la viuda" (Job 29,12-13) y más adelante: "Yo era padre de los pobres y me ocupaba de la causa del desconocido" $(29,16$; cf. Sal 68,6). La exhortación del maestro Ben Sira es más entrañable todavía: "Sé padre para los huérfanos y marido para las viudas y Dios te llamará hijo, y te consolará y te librará de la desgracia” (Sir TH6 4,10).

5 Se sigue la versión larga del texto griego según la edición crítica de Ziegler, J. (Ed.) (1965). Sapientia Iesu Filii Sirach.Septuaginta 12 (2). Göttingen: Vandenhoeck \& Ruprecht.

6 Se recurre a la versión hebrea del libro =TH, de la edición de los manuscritos de Beentjes, P. C. (Ed.) (1997). The Book of ben Sira in Hebrew. A Text Edition of All Extant Hebrew Manuscripts and a Synopsis of All Parallel Hebrew Ben Sira Text. Vetus Testamentum. Supplement 68. Leiden/New York: E. J. Brill. 
En las primeras páginas del Evangelio de Mateo es llamado José ${ }^{7}$ a adherirse en la fe, a la iniciativa divina, a convertirse en padre del bebé concebido en el seno de su prometida, el mayor regalo de Dios a la tierra, a darle un nombre y a confirmar su pertenencia a la casa de David (Mt 1,18-21). En efecto, es José quien garantiza el título cristológico a Jesús como hijo de David -de María en los Evangelios nunca se habla de que fuera de la descendencia de David- (Brown, 1982, pp. 137-142; Sacchi, 2018, pp. 56-57; Pedroli, 2019, pp. 60-61), dando así cumplimiento a la Sagrada Escritura (2 Sam 7,12-16). Por tanto, José es agraciado con la máxima bendición divina ya antes de recibir en su casa a María como esposa; está invitado a recibir a Jesús, hijo de Dios, como hijo suyo ${ }^{8}$, a abrir sus brazos para protegerlo y a educarlo como hijo bien amado (Mt 3,17; 17,7; etc.), aún sin comprender nada (Lc 2,50). Dios lo llamó a recibir primero a Jesús como hijo suyo antes que a María como esposa; es decir, en términos católicos, primero se es cristiano y, luego, mariano. Recuérdese la generalizada presentación católica de la figura de San José como protector o guardián de María antes que padre de Jesús (Pellegrino, 2014, p. 32-33).

\section{Jesús, el digno hijo de José, el carpintero}

Según los Evangelios, Jesús es conocido por sus contemporáneos y vecinos como "el hijo del carpintero" (Mt, 13,55); "el hijo de José" (Lc 4,22; Jn 6,42); "el hijo de José, el de Nazaret"” (Jn 1,45), "el carpintero" (Mc 6,3). Dos informaciones son notables: el nombre del hombre que formó a Jesús y la profesión que le enseñó ${ }^{10}$.

En la tradición bíblica, la formación de un niño es tarea de los padres $(\operatorname{Pr} 1,8 ; 6,20)$. Recomiendan los sabios: "enseña a un niño el camino que debería seguir, e incluso en una edad avanzada no se desviará de él" (Pr 22,6). La familia representa una colaboración significativa para la educación del joven en el antiguo Israel (Estes, 20 I I, pp. 15-37). La noticia sobre el oficio de Jesús y de José nos indica que: a) José cumplió la ley que manda enseñar al hijo una profesión: "Cada cual enseñará siempre a su hijo profesiones decentes y fáciles y ha de orar a Aquel de quien son la riqueza y los bienes..." (Quidushin IV,14, cf. I,7); b) Jesús aprendió de José una profesión digna y estable. Dice Ben Sira: "Enseña a tu hijo y trabaja con él, para que no tropieces con su desvergüenza" (Sir 30,13) $)^{11}$.

La palabra griega que se traduce por "carpintero" es tekton (Mt 13,55; Mc 6,3). Al parecer en el Antiguo Testamento se aplicaba a las personas que trabajaban la madera (Is Lxx 40,20; 4,13; Sab 13,11; Sir GI 38,27) y a los que trabajan el hierro o algún metal (1 Sam Lxx 13,19; 3 Re 7,2; Is Lxx 40,19; 47,1;

7 José es mencionado en Mateo unas siete veces (1,16.18.19.20.24; 2,13.19), cinco veces en Lucas $(1,27 ; 2,4.16 ; 3,23$; $4,22)$ y en Juan en dos ocasiones $(1,45 ; 6,42)$.

8 Uno de los datos evangélicos que demuestra la paternidad de José en relación a Jesús es justamente la misión de ponerle nombre (Pedroli, 2019, pp. 60-61).

9 En griego la aposición en acusativo (tòn apó Nazarét = el de Nazaret) no es referida a José sino a Jesús.

10 "El hijo de José", "el carpintero" son títulos mesiánicos (Simoens, 2002, pp. 194-196) descuidados en los manuales de cristología (González Faus, 1984, pp. 215-345; Espeja, I994, pp. 205-238).

11 Con estas deducciones de los datos evangélicos nos distanciamos de la postura de Pedroli (2019): "Sebbene Matteo non dica nulla, possiamo immaginare il ruolo chiave ricoperto da Giuseppe, nell'ambito della cura e dell'educazione del figlio" (p. 66). "Aunque Mateo no diga nada, podemos imaginarnos el papel clave que juega José en el ámbito del cuidado y de la educación de su hijo”. 
44,12). $\mathrm{La} \mathrm{Vg}^{12}$ en Mt 13,55 y Mc 6,3 la ha traducido por faber, "herrero, albañil, artesano, carpintero", mientras que, la Peshitta ${ }^{13}$ por naggara, "carpintero". De ahí la polivalencia de significados. Damos crédito a la Peshitta por su cercanía al arameo y, por tanto, habría que atenerse a la traducción "carpintero"14. Isaías 44,13a dice: "El carpintero tiende la regla, hace el trazo con un marcador, labra con la gubia, traza con el compás".

José, el carpintero, fue el mejor guía de Jesús para recorrer el camino que Dios le había pedido que abriera durante su vida oculta, alrededor de tres décadas (Lc 3,23): la búsqueda y la vivencia del sueño del Padre en las circunstancias ordinarias de la vida. Desde esta perspectiva, la parábola de Mt 24,45-47 parece reflejar la vida de José de modo acabado:

${ }^{45}$ ¿Quién, pues, es el siervo fiel y prudente, a quien su señor le puso sobre los criados de su casa, para que les diera alimentos a su debido tiempo? ${ }^{46} \mathrm{Feliz}$ será aquel siervo a quien, cuando su señor venga, le encuentre haciéndolo así. ${ }^{47} \mathrm{De}$ cierto os digo que le pondrá sobre todos sus bienes.

En otras palabras, José estuvo al lado de Jesús, formándole y enseñándole a vivir en la normalidad de la vida familiar de tradición hebrea. De José aprendió la dignidad y el valor del trabajo que en la vida adulta le llevará a descubrir y afirmar "mi Padre hasta ahora trabaja y yo también trabajo" (Jn 5,17). Con la acogida de su misión, Jesús, el carpintero, cambia de trabajo (Mc 6,3), pero sigue trabajando.

En fin, considerar la vida misionera de Jesús permite ensanchar el horizonte de interpretación y comprender la figura de José en su importante rol en la vida del hijo de Dios. En la casa de José, en Nazaret (Mt 2,23; Jn 1,45), al hijo de Dios se le podía hallar en su oficio, con el rostro sudoroso, las manos sucias y polvo de madera y piedra, listo para ofrecer su propia contribución al mundo, para llevar a cabo su papel de hombre, el hijo de José, el carpintero.

\section{De la enseñanza de la carpintería a la enseñanza de la Torá}

En los relatos de la infancia, según Mateo, se encuentran tres escenas en la que José interviene, actuando discretamente y en silencio $(1,18-25 ; 2,13-15.19-23)^{15}$. Son escenas de revelación por medio del sueño, probable reclamo a la figura del patriarca homónimo veterotestamentario, el penúltimo hijo de Jacob (Gn 37,5-9). La primera escena presenta:

12 Recurrimos a la edición de Colunga, A., \& Turrado, L. (Eds.). ('112002), Biblia Sacra Iuxta Clementinam. Nova editio. B. A. C. 14. Madrid: Biblioteca de Autores Cristianos.

13 La versión siríaca de la Biblia (del s. IV); edición disponible Online www. Cal.huc.edu.

14 La traducción castellana del sustantivo no es unánime en las diferentes ediciones de la Biblia. La traducción de las Sociedades Bíblicas Unidas $\left({ }^{3} 1994\right)$. La Biblia de Estudio. Dios Habla hoy. S.l.: Sociedades Bíblicas Unidas, ofrece la posibilidad de traducirlo "albañil”, pp. 1066, 1095. En cambio, la de Jerusalén de la edición de Urbieta, J. A. (Ed.) (1995). Biblia de Jerusalén. Nueva edición totalmente revisada y aumentada. Bilbao: Desclee de Brouwer, opta por "carpintero", pp. 1408, 1441

15 Nos atenemos a estos pasajes. Obviamos el texto de las genealogías de Jesús (Mt 1,1-17), donde también es mencionado José, porque no tiene implicaciones para nuestro foco de interés. 
${ }^{18} \mathrm{El}$ nacimiento de Jesucristo fue así: Su madre María estaba desposada con José; y antes de que se unieran, se halló que ella había concebido del Espíritu Santo. ${ }^{19}$ José, su marido, como era justo y no quería difamarla, resolvió repudiarla en secreto. ${ }^{20}$ Mientras él pensaba en esto, he aquí un ángel del Señor se le apareció en sueños y le dijo: "José, hijo de David, no temas recibir a María tu mujer, porque lo engendrado en ella es del Espíritu Santo. ${ }^{21}$ Dará a luz un hijo; y llamarás su nombre Jesús, porque él salvará a su pueblo de sus pecados" (... $)^{24}$. Cuando José se despertó del sueño, hizo como el ángel del Señor le había mandado, y acogió a su mujer. ${ }^{25} Y$ no la conocía hasta que dio a luz un hijo, y llamó su nombre Jesús (Mt 1,18-21.24-25).

José, de acuerdo a la ley, debía denunciar a María, su prometida, cuando se quedó embarazada antes de cohabitar (Dt 22,13-21). Sin embargo, para no difamarla sino salvarle el honor, valor importante de la época (Puig i Tàrrech, 2011, p. 3.409), José elude dicha ley y es calificado por Mateo, como un hombre dikaiós "justo" (v.19), y justos son aquellos que observan la ley. Aquí, aparentemente, José hace lo contrario, se resiste a cumplir la ley deuteronómica. Recurre a otra ley y es la que se halla en el corazón, la ley del amor, que significa ser fiel y leal a la persona amada. A amar se manda en la Escritura (Dt 5,6; Lv 19,18; Jn 15,12-16; etc.) porque es una actitud que se aprende (García López, 2001, p. 22). Se trata de una ley mayor; Jesús resumirá toda la ley en el amor a Dios y al prójimo (Mc 12,31 y paralelos). La decisión de José tiene como base la síntesis de la Torá: el amor.

El padre debe enseñar la Torá a su hijo. Así lo prescriben Dt 6,7; 11,19 y el tratado mísnico ${ }^{16}$ de Quiddushin IV, 14: "Rabbí Nehoray decía: Yo dejo a un lado todas las profesiones del mundo y no enseño a mi hijo más que la Torá”. Es decir, la enseñanza de la Torá es de mayor obligación para el progenitor. Por eso, habría que suponer que fue José quien introdujo a Jesús en el conocimiento de la ley de Moisés y a un modo de interpretarla (Carrasco, 1994, p. 193). Durante su ministerio público, Jesús recurre continuamente a la ley mosaica, se erige en su definitivo intérprete (Mt $5-7)$, fundamentándose en la única relación que tiene con el Padre (Mt 11,25-27). Desde el punto de vista antropológico, se podría sugerir que dicha relación tiene base en su relación con su padre José (Galot, 1995, p. 78). De él aprendió a saber discernir e interpretar la ley en su justa medida y a transgredirla en favor de otras, de bien mayor (Mc 3,1-6; Lc 6,1-11; etc.).

\section{José, el vocacionado para el cuidado del Emmanuel}

El texto de Mt 1,18-25 no nos refiere ninguna palabra de José a no ser que consideremos la importancia del verbo dicendi: "Llamar" (vv. 21.25) en boca de José; es decir, la pronunciación del nombre Jesús durante el rito de imposición con la que termina la Berit Milah o circuncisión, fundada en Gn 17,9-14. No es un dato baladí. El nombre de Jesús, en una de las propuestas de estructuración literaria del Evangelio ${ }^{17}$, tiene un peso particular: Él es el Dios con nosotros $(1,23 ; 18,20 ; 28,20)$. Por tanto, es José quien nos presenta, jurídicamente, al Dios con nosotros. Acepta con fe el misterio de su paternidad y su aceptación queda confirmada cuando pone nombre al nińo, reconociéndolo como hijo legítimo. Vivió su rol de padre con Jesús en todo y para todo (Pedroli, 2019, p. 75).

16 La Misná recoge la doctrina legal de los rabinos judíos en un periodo que abarca unos cuatrocientos años. En la forma en que nos ha llegado, la Misná fue obra de Rabí Yehudá que vivió alrededor de los años $220 \mathrm{~d}$. C.

17 Para una discusión ponderada sobre los diversos modos de fragmentar el Evangelio, véase Michelini (2007). La struttura del Vangelo secondo Matteo. Bilancio e prospettive. Rivista Biblia, 55, 313-333. 
José recibe una vocación particular; la narración de Mt 1,18-25 emplea los elementos constitutivos de un relato de vocación y anunciación (Ex 3,1-10; Jue 13,2-5; Lc 1,26-38; etc.): aparición de un mensajero divino: "Un ángel del Señor se le apareció en sueños"; la llamada por el nombre: "José, hijo de David"; la fórmula de asistencia y ánimo: "No temas"; una revelación: "Lo engendrado en ella es del Espíritu Santo. Dará a luz un hijo...” y la misión: "Llamarás su nombre Jesús". Falta el elemento de la objeción, es decir, cuando el vocacionado presenta su incapacidad o sus dudas sobre lo que se le pide (Ex 3,11; Jer 1,6; Lc 1,34). Si la objeción permite al Señor equipar a su elegido, generalmente con la promesa de la asistencia (Ex 3,12; Jer 1,6; Lc 1,35), ¿a qué se debe esta ausencia?, ¿qué significa?

La vocación de José consiste en acoger a María como esposa y a Jesús como hijo, a fundar una familia muy particular ${ }^{18}$. En la Escritura, formar una familia es un derecho consagrado y lo decide el hombre según el derecho familiar (Gn 24,1-4). Sin embargo, el Señor muchas veces trasgrede este derecho familiar. Así parece en su relación con los profetas. A Oseas le pide casarse con una mujer prostituta de los cultos al dios Baal (Os 1,2-9) ${ }^{19}$ para expresar la infidelidad de Israel (Os 1,2c). El profeta lo ejecuta sin cuestionar lo que el Señor le pide. Incluso debe contraer matrimonio con ella por segunda vez habiendo ella incurrido en la prostitución (Os 3,1-5). Y Oseas responde a la llamada del Señor sin que el autor sagrado nos informe sobre los sentimientos del profeta. Sucede con Jeremías algo semejante. A este el Señor le pide no contraer matrimonio ni engendrar hijos porque el pueblo irá al destierro y el profeta debe comunicar este mensaje al pueblo con su propia vida (Jer 16,1-4.13). En ambos casos el Señor pide a los profetas que hagan algo sorprendente, un acto que contradice la Ley: Casarse con una prostituta de los baales (Dt 7,3-5; Ex 22,13-21) o no contraer matrimonio ni engendrar hijos (Gn 26-28; 2,24; etc.). A Ezequiel, en cambio, lo convierte en viudo y sin hijos con la prohibición de hacer luto por ellos (Ez 24,15-27).

Figuras enminentes son, en la tradición bíblica, los profetas evocados, llamados por Dios a misiones de gran envergadura cuyos rasgos son inquietantes porque parece que son 'usados' por Dios sin contar con la libertad de ellos. En los tres casos, afecta la llamada de Dios no a una dimensión externa de la vida de los profetas sino en lo más íntimo de sus vidas, al mundo de los afectos (Barbiero, 2014, p. 106). El orante del Salmo 105,15 nos trasmite un oráculo que parece iluminar esta actuación del Señor en clave de amistad, de familiaridad con los profetas: "No toquen a mis ungidos; no hagan daño a mis profetas". Es decir, los profetas pertenecen al colectivo humano con el que Dios se relaciona desde una familiaridad única y, por eso, Él se atreve a pedirles que encarnen en sus vidas su mensaje, que den forma humana a su Palabra para ser transmitida al pueblo.

En el caso de San José, el evangelista necesita poner el acento en que Jesús es su hijo legal, pues según los esquemas del derecho familiar judío, la descendencia pertenece más al terreno legal que al biológico (Meier, 1991, p. 217). José se muestra disponible y al despertarse obedece la voz del ángel: "Hizo como el

18 Sobre el modo de contraer matrimonio en el mundo hebreo, véase la tesis doctoral de Tosato, A. (2001). Il matrimonio israelitico. Una teoria generale. Nova prefazione, presentazione e bibliografia. Analecta Biblia. Investigationes Scientificae in Res Biblicas 100. Roma: Editrice Pontificio Istituto Biblico.

19 Es una de las perícopas más estudiadas del libro. Son abundantes las propuestas de fragmentación del texto. Una de ellas, en Clines, D. J. A. (1979). Structure and Interpretation. En E. A. Livingstone (Ed.). Old Testament and Related Themes. Sixth International Congress on Biblical Studies, Oxford, 3 - 7 Abril, 1978. Journal for the Study of the Old Testament. Supplement 11. (pp. 83-103). Sheffield: JSOT Press. 
ángel del Señor le había mandado". De esta suerte, José inaugura una nueva forma de relaciones familiares que Jesús llevará a término al proclamar la hermandad fundada sobre la escucha, la acogida y la vivencia de la Palabra de Dios, de la voluntad de Dios (Mc 3,31-35; Mt 12,46-50; Lc 8,19-21). Se convierte, pues, en colaborador del Señor, no por iniciativa propia sino por voluntad divina, a modo de los profetas del Antiguo Testamento como Oseas, Jeremías y Ezequiel, quienes encarnaron en sus vidas la Palabra de Dios recibida para ser transmitida rompiendo con los esquemas esperados de los israelitas de su tiempo.

En resumen, gracias a la familiaridad de José con Dios, este se muestra capaz de escuchar la voz de Dios y Jesús llega a tener una familia basada en lazos que no son de carne y ni de sangre sino espirituales. De este modo, la disponibilidad y la diligencia de José abren una nueva forma de comprender y de vivir la vocación familiar que podríamos apellidar 'profética'.

\section{José, defensor y protector de la vida amenazada}

La aparición del ángel en Mt 2,13-15 obedece a una situación urgente: la vida de Jesús está bajo amenaza de exterminio por parte del poder regio. José, como padre, es llamado a defenderlo y a protegerlo huyendo a Egipto, un arriesgado viaje, de noche, a través del desierto. Un viaje que evoca el que realizaron Moisés y Séfora con su hijo Guersom de vuelta a Egipto (Ex 4,20). José se va, diligentemente, a Egipto para proteger a Jesús y a María, siguiendo las indicaciones del ángel (v. 14). Interpretado el texto, desde el punto de vista sincrónico, se deduce que mediante la diligencia de José, Jesús se salvó de la persecución de Herodes, y que la decisión es iluminada por la Escritura.

En Mateo 9,35-38 se narra la compasión de Jesús por la muchedumbre. Los vio como si fueran ovejas sin pastor. ¿De quién aprendió la diligencia para preocuparse de los indefensos? En Mateo 11,19, Jesús defiende su cercanía, en términos sapienciales, recurriendo a la figura de la Sabiduría a quien se reconoce por sus obras como es la amistad con los indefensos y pobres $(\operatorname{Pr} 31,20)$.

En este mismo Evangelio, en el discurso sobre la persecución de los misioneros (10,16-23), Jesús aconseja a los discípulos huir del hostigamiento, de una ciudad a otra ${ }^{20}$ (v. 23). Huir es un recurso de los débiles (Gn 39,12-18; Ap 12,6), de los indefensos (Ex 2,15; Jue 9,21; Hch 7,29) para ponerse a salvo de las violencias de los poderosos. Es un medio legítimo, también, para los seguidores de Jesús (Hch 8,1; 14,5; 2 Cor 11,33). En el contexto literario del logion constituye un sello de prudencia y sencillez bajo las metáforas de la serpiente y la paloma (v. 16b). Leída de este modo, la huida de José a Egipto para salvar la vida del niño indefenso legitima un medio de sobrevivencia y protección para los cristianos perseguidos. El mismo Jesús, en varias ocasiones, huirá de la persecución de sus adversarios (Jn 8,59; 10,39-40). ¿Estaba poniendo en praxis la lección aprendida?

20 Para la exégesis constituye una crux interpretum. La dificultad, fundamentalmente, radica en la discusión sobre la legitimidad cristiana del recurso a la huida en caso de persecución y el consiguiente abandono de las 'ovejas' (Luz, 2001, pp. 160-165). Más bien habría que ver la dificultad en el hecho de que sea anunciada la persecución para un tiempo muy próximo que parece contradecir la datación del libro (Stock, 2004, p. 20). 


\section{José, un amigo de Dios}

${ }^{13}$ Un ángel del Señor se apareció en sueños a José, diciendo: "Levántate; toma al niño y a su madre, y huye a Egipto. Quédate allá hasta que yo te diga, porque Herodes va a buscar al niño para matarle". ${ }^{14}$ Entonces José se levantó, tomó de noche al niño y a su madre, y se fue a Egipto. ${ }^{15} \mathrm{Y}$ estuvo allí hasta la muerte de Herodes, para que se cumpliese lo que habló el Señor por medio del profeta, diciendo: De Egipto llamé a mi hijo". ${ }^{19}$ Cuando había muerto Herodes, he aquí un ángel del Señor apareció en sueños a José en Egipto, ${ }^{20}$ diciendo: "Levántate, toma al niño y a su madre, y ve a la tierra de Israel, porque han muerto los que procuraban quitar la vida al niño”. ${ }^{21}$ Entonces él se levantó, tomó al niño y a su madre, y entró en la tierra de Israel. ${ }^{22}$ Pero, al oír que Arquelao reinaba en Judea en lugar de su padre Herodes, tuvo miedo de ir allá; y advertido por revelación en sueños, fue a las regiones de Galilea. ${ }^{23}$ Habiendo llegado, habitó en la ciudad que se llama Nazaret. Así se cumplió lo dicho por medio de los profetas, que había de ser llamado nazareno (Mt 2,13-15.19-23).

Algunos datos filológicos y narrativos son dignos de consideración: José recibe llamadas tipo órdenes y las ejecuta. No presenta ninguna objeción ni es consultado sobre su voluntad de hacerlo: vv. 13-14.2021. En ambos casos, como también en 1,24: "cuando José despertó del sueño, hizo como el ángel del Señor le había mandado, y recibió a su mujer”. José no argumenta, no objeta, no se rebela. Realiza cada gesto, cada mandato como si fuera el más común de la vida ordinaria: "José se levantó, tomó de noche al niño y a su madre, y se fue, una vez a Egipto, y otra vez vuelve de Egipto..." (vv. 14.21). En este punto, normalmente, se insiste en la obediencia de José (Luz, 1993, pp. 178, 180; Perrot, 2000, p. 35; Reid, 2005, p. 16; Pattarumadathil, 2012, p. 23). Puede preguntarse, sin embargo, ¿cuál es el fundamento de la obediencia de José? ¿a qué se debe qué Dios lo trate de este modo? y ¿por qué José no presenta su interrogante como María en Lc 1,34?

A nuestro parecer, el trato que José recibe de parte de Dios y su modo de comportarse se comprenden a la luz de la amistad de entreambos. José es llamado “justo" en Mateo 1,19, y los justos, en la Escritura, son considerados amigos de Dios (Sant 2,23). Se necesita un fuerte vínculo de amistad y de confianza para pedirle convertirse en inmigrante, en la tierra del conocido históricamente, hostil Egipto.

Los aspectos concretos que hemos abordado anteriormente evocan, además de Oseas, Jeremías y Ezequiel, "profetas a la fuerza" (Römer, 2014, p. 115) - -, la figura de Abraham, el "amigo de Dios" (Is 41,8, 2 Cro 20,7; Sant 2,23), cuando es llamado a dejar todo tipo de seguridad como son la tierra y la casa paterna, la patria, y a acoger un viaje hacia lo desconocido: "Y el Señor dijo a Abraham: vete de tu tierra, de entre tus parientes y de la casa de tu padre, a la tierra que yo te mostraré" (Gn 12,1). Y la respuesta de Abraham no se dejó esperar: "entonces Abraham se fue tal como el Señor le había dicho; y Lot fue con él. Y Abraham tenía setenta y cinco años cuando partió de Harán” (v. 4). El texto narra que Abraham abandona su pasado sin dudar e igualmente lo hará cuando Dios le pida ofrecer su hijo en sacrificio (Gn 22,1-19). El trato que Dios dispensa a Abraham denota una familiaridad, una amistad muy particular. Una relación de amistad-implica complicidad y osadía para pedir algo, sabiendo que el amigo no se echará atrás (Ska, 2013, p. 176). Relación de confianza que no cambia con los años sino que se afianza y se alimenta en cada gesto.

A la luz de la precedente consideración emerge la figura de José, un hombre habituado a tomar decisiones como amigo de Dios. Y en los tres episodios de Mt 1,18-25; 2,13-15.19-23, cada gesto operado 
por José es acompañado por la afirmación del cumplimiento de la Escritura ${ }^{21}$ y por eso, con razón fundada, el evangelista lo llama "el hombre justo" (O'Rourke, 1962, p. 395). En la literatura sapiencial, el hombre justo es sinónimo del hombre sabio (Pr 10,31; 11,30; 17,27-28). El hombre sabio es aquel que sabe guardar silencio y tomar las decisiones correctas (Mancuello, 2010, pp. 80-81), tiene gran estima por la amistad: "el amigo ama en toda ocasión, el hermano nace para el tiempo de angustia", enseña Pr 17,17. Las palabras amigo y hermano son empleadas en relación de paralelismo sinonímico que dice correspondencia de sentido. Es decir, amistad en toda ocasión, incluido el tiempo de angustia.

Los amigos se buscan, se encuentran, se guardan sorpresas. No todo se comprende, pero no se abandonan (Pr 27,10; Sir 9,10). Es enseñanza de los sabios bíblicos que los amigos son dones de Dios. El maestro Ben Sira afirma:

${ }^{14}$ Un amigo fiel es protección segura, quien lo encuentra, encuentra un tesoro.

${ }^{15}$ Un amigo fiel no tiene precio,

Su precio es incalculable.

${ }^{16}$ Un amigo fiel es remedio saludable,

los que respetan al Seńor lo encuentran (6,14-16).

Lucas, en la escena de la presentación, al lado de María ${ }^{22}$ (Lc 2,22-38), nos muestra a José, de corazón sencillo, que se sorprende y se admira de las cosas que se dicen del niño Jesús (v. 33), Jesús es una bendición para él (v. 34). En Lc 2,41-50, José aparece como un hombre que busca a Jesús (v. 44), lo encuentra (v. 46), se sorprende de ciertos comportamientos del adolescente (v. 48), no los comprende pero no le abandona, le sigue acompañando con un silencio contemplativo y educativo en su casa de Nazaret (v. 50-51).

\section{José, el hombre contemplativo del Dios con nosotros}

En Mt 2,11 leemos: "Entraron en la casa, vieron al niño con María y su madre, y cayendo de rodillas lo adoraron; después, abriendo sus cofres, le ofrecieron regalos: oro, incienso y mirra". En este contexto aparece María, junto al niño, en una escena entrańable en la que ninguno de los personajes pronuncia una sola palabra. Las presencias y los gestos hablan y comunican lo acontecido. María se encuentra en casa, símbolo del hogar y de la intimidad que a nadie excluye, en donde recibe la visita de desconocidos.

José no es nombrado explícitamente. ¿Dónde está José? La narración y el contexto literario (v. 13-15) permiten verlo adorando al bebé, Dios con nosotros. Así lo han entendido los artistas. Él está en casa, es el pater familias, y contempla al hijo, admirando el misterio que había puesto en crisis su amor y su

21 Sobre los tipos de fórmulas de cumplimientos empleados en los primeros capítulos de Mateo véase el estudio cuidadoso de Hamilton, J. M., Jr (2008). The Virgin Will Conceive: Typological Fulfillment in Matthew 1,18-23. En D. M Gurtner \& J. Nolland (Eds.). Built upon the Rock. Studies in the Gospel of Matthew (pp. 228-247). Grand Rapids, Michigan - Cambridge, U.K.: Williams B. Eerdmans Publishing Company.

22 Todos los versículos citados tienen el verbo en plural. Hacen referencia a los padres de Jesús: v. 33: qauma,zontej "estaban asombrados"; v. 44: avnezh,toun "buscan"; v. 46: eu-ron "encontraron"; v. 48: evxepla,ghsan "se quedaron sorprendidos"; v. 48: evzhtou/me,n se "te buscábamos", v. 50: ouv sunh/kan "no comprendieron". 
amistad con María (Mt 1,19). Envuelto en el silencio y en la contemplación, José empieza a comprender y a sentirse parte del sueño de Dios. En su silencio descubrimos la invitación a la contemplación del Dios con nosotros, la Shekinah, hecho ternura en la carne de un bebé recién nacido; un símbolo de creyente y de persona contemplativa.

\section{Conclusiones}

Estudiar los textos evangélicos que mencionan a José, examinarlos e interpretarlos en estrecha relación con los textos del Antiguo Testamento permiten comprender su figura en el seno de su propia tradición religiosa, poniendo de relieve su intimidad con Dios, su relación con Jesús, su hijo, formado por él en el trabajo, en la relación con Dios y con sus semejantes. Y, sobre todo, nos sugiere respuestas a nuestros interrogantes acerca de porqué José se calla y acoge sin titubeos los requerimientos más sorprendentes de Dios, quien no le ofrece oportunidad de protestar, de preguntar ni de presentar objeciones. Un trato de parte de Dios y una correspondencia de parte de José que tantas veces han desconcertado a los cristianos.

Hemos visto que Abraham fue llamado a acometer una misión de gran envergadura y él respondió sin vacilación, sin protestar y fue llamado amigo de Dios por Is 41,8. Asimismo, los profetas Oseas, Jeremías y Ezequiel fueron llamados y 'obligados' a identificarse existencialmente con el mensaje del Señor que debían transmitir al pueblo, asumiendo vocaciones que afectaban directamente sus estados de vida. En lugar de protestar o de cuestionar, ellos acogieron esa Palabra del Señor y la padecieron en carne propia en arasde la credibilidad del mensaje. El Señor advirtió al pueblo, por boca del salmista, acerca de su relación con ellos: "No toquen a mis ungidos; no hagan daño a mis profetas" (Sal 105,15). Colocar a José a la luz de tales figuras bíblicas nos autoriza sugerir que la clave de lectura de su modo de corresponder al trato de Dios sea el de luna profunda amistad, familiaridad e intimidad con Él. Este le pide, con tranquila osadía, que acoja en su casa a su esposa embarazada y que sea el padre del Emmanuel, una llamada pratriarcal-profética. Asimismo, la de proteger y defender la vida amenazada de la Palabra de Dios, encarnada en el seno de su hogar. Esta clave de lectura nos evoca la célebre y simpática frase de Teresa de Ávila: "terriblemente trata Dios a sus amigos" (Cta. 233), refiriéndose a los sufrimientos de Juan de la Cruz.

\section{San José, el gran amigo de Teresa de Jesús}

Promover la amistad con san José fue una práctica constante de Teresa de Ávila (+1582). Ella emerge justo a los inicios de "la aparición oficial de san José en la Iglesia por la reforma del Breviario (1568) y el Misal (1570), en los cuales Pío V inscribe la fiesta del santo con rito doble" (Stramare, 1983, p. 10). Es significativo señalar que el Patriarca ha sido objeto de atención esporádica por parte de escritores cristianos desde el siglo II, como Justino, Orígenes, e Ireneo, y ha recibido un tratamiento sistemático en la teología católica desde el siglo XVII, cuando se sugirió comprender su misión en el orden hipostático (López González, 2020, p. 84).

A propósito de su rol en la espiritualidad cristiana, sin embargo, al parecer, llega a la Iglesia latina a través de la orden del Carmelo, nacida en Palestina, tierra del Patriarca. En efecto, la festividad de san José en el Carmelo es de datación relativamente antigua, pues se celebra desde la segunda mitad del siglo XV 
con oficio propio, el más antiguo oficio conservado en la Iglesia latina (Xiberta, 1964, pp. 301-319). Es en el seno de la orden del Carmelo donde acudimos para encontrarnos con Teresa de Jesús, pues según la investigación de Tomás Álvarez (2006),

El humus en que brotó esa su devoción fue sin duda la tradición espiritual de su familia carmelita y de su monasterio de la Encarnación, con los fiorettis y leyendas de los orígenes de la Orden y con la festividad de San José, presente en el breviario carmelitano y en el misal de la Orden (p. 374).

Santa Teresa de Jesús: doctora de la Iglesia, maestra de oración. Así la reconoce la Iglesia. Y entre esos apelativos se podría agregar otro de no menor importancia: gran amiga de San José, porque la relación que tuvo con él fue tan familiar y de una confianza tan plena, que genera, en quien lee sus escritos, asombro, inspiración y admiración.

En este aporte queremos destacar, precisamente, la relación de amistad y de familiaridad que tuvo Teresa con San José. Contribución que ojalá pueda ayudar a las lectoras y lectores a cultivar la confianza en él, a tomarlo por amigo y abogado, como lo hizo la santa.

\section{La relación de intimidad con Dios}

Raniero Cantalamessa, en el año 2019, durante los ejercicios espirituales de cuaresma predicados a la curia romana, y en los que estuvo presente el papa Francisco, dijo claramente: "la interioridad es un valor en crisis". Tal vez sea un valor que, a lo largo de la historia, tuvo sus altibajos como tantos otros aspectos de la vida espiritual. De hecho, leemos en el libro de Isaías: "Este pueblo me alaba con la boca, y me honra con los labios, pero su corazón está lejos de mí y el culto que me rinden es puro precepto humano, simple rutina" (Is 29,13-14). Con este mismo pasaje Jesús les respondió a los fariseos y maestros de la ley que lo cuestionaron porque sus discípulos no se lavaban las manos para comer (Mt 15,7-9). Otro texto bíblico muy sugerente proclama: "La mirada de Dios no es como la del hombre, el hombre ve las apariencias, pero el Señor ve el corazón” (1Sam 16,7). En efecto, en este momento de la historia, el ser humano tiende a estar fuera de sí, y las redes sociales han tenido -y tienen- un impacto enorme sobre las personas. A través de ellas, fácilmente nos mantenemos distraídos, entretenidos, fragmentados por dentro y por fuera. Resultado: la persona humana de hoy es casi incapaz de hacer silencio para encontrarse con Aquel que la habita.

Como contrapartida, el texto sagrado del libro de Samuel nos dice que Dios no se queda en las apariencias sino que, más bien, mira el corazón de las personas. San Agustín, ya en el siglo IV de nuestra era, quien también había tenido sus muchas distracciones, se entristecía al darse cuenta de que Dios no

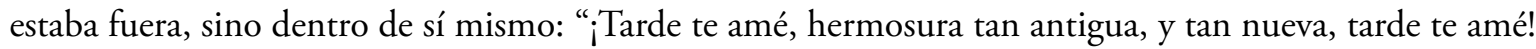
Y he aquí que estabas tú dentro de mí, y fuera te buscaba yo y sobre esas hermosuras que tú creastes me arrojaba deforme" (Conf. X, 27, 38).

En la tradición espiritual cristiana católica, en concreto aquella carmelitana, ha habido santos y santas que han cultivado de una manera exquisita la vida interior y, en la cumbre de esta tradición, hallamos a Santa Teresa de Jesús. Ella emplea la imagen del castillo interior para describir quién es la persona humana y quién la habita: ... "que es considerar nuestra alma como un castillo todo de un diamante o muy claro 
cristal, adonde hay muchos aposentos, así como en el cielo hay muchas moradas” $\left(1 \mathrm{M}^{23} 1,1\right)$, “. . y en el centro y mitad de todas éstas tiene la más principal, que es adonde pasan las cosas de mucho secreto entre Dios y el alma” (1M 1,3).

Cada momento de la vida es un tiempo propicio, "pues sepan que éste es el tiempo favorable" (2 Cor 6,2), y, por eso, siempre estamos a tiempo para volver la mirada a lo que es esencial en nuestra vida, como tantos hombres y mujeres a lo largo de la historia que supieron redescubrir "la fonte que mana y corre, aunque es de noche" (San Juan de la Cruz, 1993, p. 76). Santa Teresa enseña ${ }^{24}$ :

Pues mirad que dice San Agustín que le buscaba en muchas partes y que le vino a hallar dentro de sí mismo. ¿Pensáis que importa poco para un alma derramada entender esta verdad y ver que no ha menester para hablar con su Padre Eterno ir al cielo, ni para regalarse con El, ni ha menester hablar a voces? Por paso (=por muy bajo) que hable, está tan cerca que nos oirá. Ni ha menester alas para ir a buscarle, sino ponerse en soledad y mirarle dentro de sí y no extrañarse de tan buen huésped $\left(C^{25} 28,2\right)$.

Teresa tuvo una viva conciencia de la presencia de Dios en su vida, en su interior, conciencia que ha dejado como herencia y enseñanza a la Iglesia que la invoca como su maestra, su doctora. Si la vida interior está en crisis, ¿̨no será momento de tomar nosotros la determinación de volver nuestra mirada a Él, como lo han hecho los santos a lo largo de la historia de la Iglesia? Ellos se han convertido en grandes instrumentos del amor de Dios, supieron apreciar y valorar el silencio y la soledad: "Una palabra habló el Padre, que fue su Hijo, y ésta habla siempre en eterno silencio, y en silencio ha de ser oída del alma" (San Juan de la Cruz, 1993, p. 104).

Para emprender ese camino desafiante, escuchemos lo que nos dice Teresa sobre San José: "Quien no hallare maestro que le enseñe oración, tome este glorioso Santo por maestro y no errará en el camino”. Ella descubrió, en el silencio de San José, la vida interior o de oración que habría llevado el padre de Jesús. Y esta vida de oración se manifestó, claramente, en su docilidad para realizar con obediencia lo que el ángel le había indicado: "Cuando José se despertó del sueño, hizo lo que el ángel del Señor le había mandado" (Mt 1,24). Entró en contacto con el santo desde su sufrimiento, su floja salud física.

\section{Teresa y su debilitada salud}

Santa Teresa era una mujer de muy poca salud; ella misma nos cuenta como fue hasta Becedas con la intención de tratarse con una médica (naturista como diríamos hoy):

Estuve en aquel lugar tres meses con grandísimos trabajos, porque la cura fue más recia que pedía mi complexión. A los dos meses, a poder de medicinas, me tenía casi acabada la vida, y el rigor del mal de

23 La $\mathbf{M}=$ Las Moradas o Castillo Interior.

24 Sobre la voluntad pedagógica de los escritos de Teresa, véase el estudio de Mancho Duque, M. J. (2014). Claves de la escritura teresiana. Salamanca Revista de Estudios, 59, 107-109.

25 La C = Camino de Perfección. 
corazón de que me fui a curar era mucho más recio, que algunas veces me parecía con dientes agudos me asían de él, tanto que se temió era rabia. Con la falta grande de virtud (porque ninguna cosa podía comer, si no era bebida, de grande hastío) calentura muy continua, y tan gastada, porque casi un mes me había dado una purga cada día, estaba tan abrasada, que se me comenzaron a encoger los nervios con dolores tan incomportables, que día ni noche ningún sosiego podía tener. Una tristeza muy profunda $\left(\mathrm{V}^{26} 5,7\right)$.

Con esto no terminó la enfermedad de Teresa. Al contrario, se fue agudizando hasta, incluso, entrar en coma cerca de cuatro días, cuando estuvieron a punto de darla por muerta ${ }^{27}$. Nos dice:

Diome aquella noche un paraxismo (= estado de coma) que me duró estar sin ningún sentido cuatro días, poco menos. En esto me dieron el Sacramento de la Unción y cada hora o momento pensaban expiraba y no hacían sino decirme el Credo, como si alguna cosa entendiera. Teníanme a veces por tan muerta, que hasta la cera me hallé después en los ojos (V 5,9).

Extraordinario es como Teresa supo sobrellevar estos momentos duros que le tocó afrontar y, por eso, vale la pena seguir escuchando su relato de cómo siguió después de estar cuatro días en coma:

Quedé de estos cuatro días de paroxismo de manera que sólo el Señor puede saber los incomportables tormentos que sentía en mí: la lengua hecha pedazos de mordida; la garganta, de no haber pasado nada y de la gran flaqueza que me ahogaba, que aun el agua no podía pasar; toda me parecía estaba descoyuntada; con grandísimo desatino en la cabeza; toda encogida, hecha un ovillo, porque en esto paró el tormento de aquellos días, sin poderme menear, ni brazo ni pie ni mano ni cabeza, más que si estuviera muerta, si no me meneaban; sólo un dedo me parece podía menear de la mano derecha. Pues llegar a mí no había cómo, porque todo estaba tan lastimado que no lo podía sufrir. En una sábana, una de un cabo y otra de otro, me meneaban (V 6,1).

Hasta ahora Teresa se encuentra en la casa de su familia y desea volver al monasterio lo antes posible, y así lo hizo: "Dí luego tan gran prisa de irme al monasterio, que me hice llevar asî" (V 6,2). Su modo de afrontar la enfermedad sorprendía, también, a sus contemporáneos: "Se espantaban de la paciencia que el Señor me daba; porque, a no venir de mano de Su Majestad, parecía imposible poder sufrir tanto mal con tanto contento" (V 6,2).

26 La $\mathbf{V}=$ Libro de la Vida.

27 Ribera Vida, I, 1 nos cuenta que "la sepultura estaba abierta en la Encarnación, y estaban esperando el cuerpo para enterrarle, y monjas estaban allí [en casa de D. Alonso] de la Encarnación que habían enviado para estar con el cuerpo, y hubiéranla enterrado si su padre no lo estorbara muchas veces contra el parecer de todos, porque conocía mucho el pulso y no podía persuadir que estuviese muerta; y cuando le decían que se enterrase, decía: “esta hija no es para enterrar". Velándola una noche de estas Lorenzo de Cepeda, su hermano, se durmió, y una vela que tenía sobre la cama se acabó, y se quemaban las almohadas y mantas y colcha de la cama, y si él no despertaba al humo, se pudiera quemar o acabar de morir la enferma”. (Citado en Santa Teresa de Jesús, 1997, p. 37) 


\section{San José en la vida de Teresa}

El estado de salud de Teresa puede parangonarse con el de aquella mujer del Evangelio de Mc 5,25-26: "que padecía hemorragias desde hacía doce años, y que había sufrido mucho con los médicos, que había gastado todo lo que tenía sin provecho alguno y más bien había empeorado”. De quien más adelante nos sigue diciendo el evangelista: "oyó hablar de Jesús, se acercó por detrás entre la gente y tocó su manto. Pues decía: si logro tocar aunque sólo sea su manto, quedaré sana” (5,27-28). Efectivamente, Jesús le dice: "Hija, tu fe te ha salvado; vete en paz; estás liberada de tu mal" $(5,34)$.

En el caso de Santa Teresa de Jesús, después de haber peregrinado buscando la cura a su mal y acudiendo a los médicos de la tierra, no encontró salida. Y, como la mujer del evangelio, que acudió a Jesús para que la sanara, Teresa acudirá a los médicos del cielo:

Pues como me vi tan tullida y en tan poca edad (entre 26/27 años, hacia 1542) y cuál me habían parado los médicos de la tierra, determiné acudir a los del cielo para que me sanasen; que todavía deseaba la salud, aunque con mucha alegría lo llevaba, y pensaba algunas veces que, si estando buena me había de condenar, que mejor estaba así; mas todavía pensaba que serviría mucho más a Dios con la salud. Este es nuestro engaño, no nos dejar del todo a lo que el Señor hace, que sabe mejor lo que nos conviene (V 6,5).

Tras muchas búsquedas Teresa nos cuenta que, a quien ella llega a encontrar, es al médico del cielo: "Y tomé por abogado y señor al glorioso San José y encomendéme mucho a él. Vi claro que así de esta necesidad como de otras mayores de honra y pérdida de alma este padre y señor mío me sacó con más bien que yo le sabía pedir" (V 6,6). En esta última cita podemos apreciar claramente la confianza plena que ella depositó en San José, y desde su propia experiencia nos comunica -con mucha convicción- que su amigo San José siempre la escuchó y acudió a sus necesidades de alma y cuerpo: "No me acuerdo hasta ahora haberle suplicado cosa que la haya dejado de hacer. Es cosa que espanta las grandes mercedes que me ha hecho Dios por medio de este bienaventurado Santo, de los peligros que me ha librado, así de cuerpo como de alma" (V 6,6).

Como si la piedad popular se hubiera adelantado a nuestra época en la que el avance de las Ciencias Médicas han hecho que se multipliquen las especialidades, la transmisión oral de la fe adjudica, a cada santo, una especialidad: así tenemos en san Cristóbal o en san Rafael a los patronos de los viajeros, o en santa Lucía a la patrona de las enfermedades oculares. Teresa, asumiendo que tener una especialidad implicaría limitar su intercesión, atribuye a San José, la capacidad de auxiliar en cualquier necesidad, sin restricciones. Por eso, con su contundente sencillez, nos dice:

(...) A otros santos parece les dio el Seńor gracia para socorrer en una necesidad, a este glorioso Santo tengo experiencia que socorre en todas y que quiere el Señor darnos a entender que así como le fue sujeto en la tierra -que como tenía el nombre de padre, siendo ayo, le podía mandar-, así en el cielo hace cuanto le pide (V 6,6).

Por eso, Teresa invita a sus lectores de todos los tiempos a acudir a San José con toda confianza; porque ella es la primera en haber experimentado que su amigo siempre la escuchó e intercedió por ella: "Esto han visto otras algunas personas, a quien yo decía se encomendasen a él, también por experiencia; y aún hay 
muchas que le son devotas de nuevo, experimentando esta verdad" (V 6,6). Y, para que realmente estén convencidos que san José no falla, Teresa seguirá insistiendo a sus lectores:

Procuraba yo hacer su fiesta con toda la solemnidad que podía, más llena de vanidad que de espíritu, queriendo se hiciese muy curiosamente y bien, aunque con buen intento. Querría yo persuadir a todos fuesen devotos de este glorioso Santo, por la gran experiencia que tengo de los bienes que alcanza de Dios. No he conocido persona que de veras le sea devota y haga particulares servicios, que no la vea más aprovechada en la virtud; porque aprovecha en gran manera a las almas que a él se encomiendan. Paréceme ha algunos años que cada año en su día le pido una cosa, y siempre la veo cumplida. Si va algo torcida la petición, él la endereza para más bien mío (V 6,7).

Teresa quedó plenamente convencida que al santo se debió su total sanación. La firme convicción de haber recuperado la salud, por obra y gracia -o por puro milagro- de San José, hace que le tenga confianza y devoción al Patriarca, no sólo para pedirle salud o cosas materiales, sino también, y sobre todo, bienes espirituales.

\section{San José, un maestro de oración}

Santa Teresa es invocada y proclamada por la Iglesia como maestra de oración o maestra de ejercicios espirituales. Ella nos aconseja, sin embargo, que tomemos a San José por maestro de oración, sin temor a equivocarnos en el camino:

Si fuera persona que tuviera autoridad de escribir, de buena gana me alargara en decir muy por menudo las mercedes que ha hecho este glorioso Santo a mí y a otras personas; mas por no hacer más de lo que me mandaron, en muchas cosas seré corta más de lo que quisiera, en otras más larga que era menester; en fin, como quien en todo lo bueno tiene poca discreción. Sólo pido por amor de Dios que lo pruebe quien no me creyere, y verá por experiencia el gran bien que es encomendarse a este glorioso Patriarca y tenerle devoción. En especial, personas de oración siempre le habían de ser aficionadas; que no sé cómo se puede pensar en la Reina de los ángeles en el tiempo que tanto pasó con el Nińo Jesús, que no den gracias a San José por lo bien que les ayudó en ellos. Quien no hallare maestro que le enseñe oración, tome este glorioso Santo por maestro y no errará en el camino. Plega al Señor no haya yo errado en atreverme a hablar en él; porque aunque publico serle devota, en los servicios y en imitarle siempre he faltado (V 6,8).

Esta exhortación de Teresa, como puede deducirse del texto, tiene dos fundamentos. En primer lugar, su propia experiencia corroborada con las de los otros: "las mercedes que ha hecho este glorioso Santo a mí y a otras personas". En primera persona testimonia que verificó, en su propia vida, la fidelidad de San José en la asistencia espiritual. Por eso, insiste en que se haga experiencia del "gran bien que es encomendarse a este glorioso Patriarca y tenerle devoción. En especial, personas de oración siempre le habían de ser aficionadas". En segundo lugar, Teresa menciona la proximidad, la familiaridad de San José con María y Jesús: "La Reina de los ángeles en el tiempo (...) pasó con el Niño Jesús, que no den gracias a San José por lo bien que les ayudó en ellos”. En otras palabras, según la enseñanza de Teresa, San José está agraciado para darnos su mano y conducirnos a una relación con Jesús y con María, en clima de familia. 
En un lenguaje sumamente sugerente, la maestra de oración de la Iglesia propone a quienes quieran ser "personas de oración" o bien a quienes les cuesta orar y lo desean, o "quien no hallare maestro ${ }^{28}$ que le enseñe oración". Es el verbo propone de la primera línea. "aficionarse a San José". El verbo empleado "aficionarse" denota aprecio, carińo, simpatía y lleva la marca de la constancia. En pocas palabras, Teresa nos invita acostumbrarnos a San José desde la simpatía, el cariño y el aprecio.

Tal como se ha subrayado en la primera parte del artículo no encontramos ni una palabra de San José en los Evangelios; sólo gestos de obediencia y disponibilidad a los planes de Dios a causa de su amistad y familiaridad con Él. Por eso, se habla de él en la Iglesia como el hombre del silencio, contemplativo, obediente y siempre disponible a la voz del Señor. Tal vez sea el silencio que acoge y denota complicidad, la clave para cultivar y alimentar la relación íntima y profunda con el Señor. De este modo nos resultaría más fácil escucharle "en el más profundo centro" (San Juan de la Cruz, 1993, pp. 790-791) de nuestra alma. Es en esta línea, a nuestro juicio, en la que José es presentado y ofrecido por Teresa como maestro de oración, guía del "trato de amistad con quien sabemos nos ama" (V. 8,5). Y ¿quién más que José al lado de María, en silencio contemplativo, vivió en un trato de amistad con el Señor, cuidando, alimentando, sirviendo, educando a su Hijo hecho hombre?

Expresiones como: "Mi padre san José” (V 33,14), "mi padre glorioso san José” (V 36,6); “hice oración suplicando... a mi padre san José que me trajese a su casa" (V 36,11) denotan una gran cercanía en el trato. Se trata de unas de las amistades de Santa Teresa que bajo el nombre de devoción tuvo una gran influencia en el catolicismo occidental, empezando por su entorno. Durante su vida, de los quince monasterios que fundó, nueve fueron encomendados al patrocinio de San José, inciando con la primera fundación: San José de Ávila (Sánchez-Reyes, 2014, pp. 46-62). Aún después de su muerte, muchas carmelitas cambiaron su patronímico por el "de san José"29.

Esta influencia, sin embargo, no ha quedado relegada al Carmelo; se ha extendido a toda la Iglesia, culminando con el nombramiento, por parte del papa Pío IX en su decreto Quemadmodun Deus, a pedidos de ciento cincuenta y tres obispos y cuarenta y tres superiores de órdenes religiosas (Juan XXIII, I96I, pp. 205-213), de nombrar a San José como Patrono Universal de la Iglesia, el 8 de diciembre de 1870. El pontífice establece su liturgia propia a rito doble de primera clase el día 19 de marzo (1873, p. 282). Por lo cual, en este año 2020 , estamos cumpliendo el $150^{\circ}$ aniversario de esta gracia eclesial.

28 Una obra completa acerca de las figuras que la santa tomó por maestros en otras materias es la de: De Pablo Maroto, D. (2009). Lecturas y maestros de Santa Teresa. Madrid: Editorial de Espritualidad.

29 Un detalle curioso de carácter historio-geográfico de los pueblos de lengua castellana nos refiere Tomás Álvarez (2006): "Aunque aparentemente se trate de una minucia, ese cambio es revelador del rápido ingreso de san José en la toponimia universal, en coincidencia (y quizás en dependencia) del cambio producido a escala social y geográfica mundial. Mientras en la toponimia castellana anterior a Teresa abundan las poblaciones con nombre de innumerables santos (San Pedro, San Juan, San Martín, San Nicolás, Santa Eulalia...) menos el de San José, de pronto (ss. XVI-XVII) el Santo Patriarca da nombre a un sinnúmero de poblaciones de toda América hispana, desde los Estados Unidos de América hasta Argentina y Filipinas" (p. 380). 
El influjo de Teresa en la propagación de la devoción a San José en el catolicismo occidental será reconocido por Juan Pablo II en su Exhortación Apostólica Redemptoris Custos, número 25:

También el trabajo de carpintero en la casa de Nazaret está envuelto por el mismo clima de silencio que acompaña todo lo relacionado con la figura de José. Pero es un silencio que descubre de modo especial el perfil interior de esta figura. Los Evangelios hablan exclusivamente de lo que José "hizo"; sin embargo, permiten descubrir en sus "acciones" —ocultas por el silencio— un clima de profunda contemplación. José estaba en contacto cotidiano con el misterio "escondido desde siglos", que «puso su morada» bajo el techo de su casa. Esto explica, por ejemplo, por qué Santa Teresa de Jesús, la gran reformadora del Carmelo contemplativo, se hizo promotora de la renovación del culto a san José en la cristiandad occidental.

Es de señalar, en cambio, que la nota dominante es la devocional. En la misma línea, con algunos matices, se ubica el primer documento amplio y extenso dedicado a San José hecho por un pontífice: el papa León XIII, en 1889, la Carta Quamquam pluries. En ella, en su número 5, el Papa ensalza a José como modelo de padres de familia y trabajadores. Al término del escrito ofrece una oración al santo, de raigambre marcadamente proteccional, que denota una relación afectiva y efectiva. Por tanto, la figura de José es uno de los tesoros que la Iglesia ha estimado y ha conservado en su seno espiritual.

Bajo la protección, el nombre y el carisma de san José, el Espíritu Santo ha generado una multiplicidad de congregaciones religiosas, femeninas y masculinas, en la Iglesia que ven en el santo al verdadero maestro de la vida interior, modelo de unión con Dios y de servicio al prójimo (Stramare, 1983, p. 14). En efecto, en los siglos XIX y XX surgieron más de doscientas congregaciones josefinas, muchas de ellas de inspiración carmelita. Muchos dicenque el XIX es "el siglo de san José" (Stramare, 1983, pp. 9-23).

\section{Conclusiones}

La persona de San José fue inspirante en la espiritualidad de Santa Teresa de Jesús hasta el punto que nos la propone como maestro de oración después de que ella misma lo haya tomado por médico, abogado y maestro. Es una faceta de Teresa que sigue perfectamente la tradición bíblica porque si de trato de amistad con Dios se trata, José, el amigo de Dios, el padre y maestro de Jesús, es una de las figuras creyentes más inspirantes e intrigantes que los Evangelios conocen, narran, aman y conservan en sus páginas. Y la historia de la Iglesia testimonia que la espiritualidad cristiana católica la transmite y la experimenta de generación en generación como don de Dios bajo el carácter devocional. ¿No será el momento de retomar algunas líneas de espiritualidad menos conocidas como la de acoger su persona como maestro de oración, un hombre de profunda experiencia humana y amigo de Dios?

\section{Referencias}

Aland, K., et al. (Eds.). $\left({ }^{27} 1993\right)$. Novum Testamentum Graece. Stuttgart: Deutsche Bibelgesellschaft.

Álvarez, T. (2006). San José. En Diccionario de Santa Teresa. Doctrina e Historia (pp. 374-389). Burgos: Monte Carmelo. 


\section{San José en la Sagrada Escritura y en la espiritualidad}

Barbiero, G. (2014). “Mi hai sedotto, Signore”. Le confessioni di Geremia alla luce della sua vocazione profetica. Roma: Gregorian \& Biblical Press.

Brändle, F. (1982). Imagen bíblica de san José en Santa Teresa. Estudios Josefinos, 36, 283-300.

Beentjes, P. C. (Ed.). (1997). The Book of ben Sira in Hebrew. A Text Edition of All Extant Hebrew Manuscripts and a Synopsis of All Parallel Hebrew Ben Sira Text. Vetus Testamentum. Supplement 68. Leiden/New York: E. J. Brill. https://doi.org/10.1163/9789004275928

Brown, R. E. (1982). El nacimiento del Mesías. Comentario a los relatos de la infancia. Madrid: Ediciones Cristiandad.

Cantalamessa, R. (2019, 22 de marzo). La disipación es la enfermedad mortal que amenaza a todos. Recuperado de https:/www.vaticannews.va/es/papa/news/2019-03/segunda-predicacion-cuaresma-padre-cantalamessadisipacion-vida.html .

Carrasco, J. A. (1994). La paternidad de José sobre Cristo. ¿Necesita una nueva reflexión? Teresianum, 45, $185-194$.

Carrasco, J. A. (1993). Influencia negativa de los apócrifos en la Josefología. Estudios Josefinos, 47, 29-45.

Clines, D. J. A. (1979). Hosea 2: Structure and Interpretation. En E. A. Livingstone (Ed.). Old Testament and Related Themes. Sixth International Congress on Biblical Studies, Oxford, 3 - 7 Abril, 1978. Journal for the Study of the Old Testament, Supplement 11 (pp. 83-103). Sheffield: JSOT Press.

Colunga, A., \& Turrado, L. (Eds). (112002). Biblia Sacra Iuxta Clementinam. Nova editio. B. A. C.14. Madrid: Biblioteca de Autores Cristianos.

Del Valle, C. (Ed.). (22003). La Mishná. Biblioteca de Estudios Bíblicos 98. Salamanca: Sígueme.

Elliger, K., \& Rudolph, W. (Eds.). (51997). Biblia Hebraica Stuttgartensia. Stuttgart: Deutsche Bibelgesellschaft.

Espeja, J. (1994). Hemos visto su gloria. Introducción a la Cristología. Glosas 25. Salamanca: San Esteban.

Estes, D. J. (2011). Ascolta figlio mio. La pedagogia del libro dei Proverbi. Studio di Teologia Biblica 2. Roma: Edizione GBU.

Galot, J. (1995). Giuseppe l'educatore. Il Gesù nuovo, 60 (2), 74-78.

García López, F. (2001). El Deuteronomio, una ley predicada. Cuadernos Bíblicos 63. Estella: Verbo Divino.

González Faus, J. I. ( $\left.{ }^{7} 1984\right)$. La humanidad nueva. Ensayo de Cristología. Presencia Teológica 16. Santander: Sal Terrae.

Hamilton, J. M., Jr (2008). The Virgin Will Conceive: Typological Fulfillment in

Matthew 1,18-23. En Gurtner, D. M., \& Nolland, J. (Eds.). Built upon the Rock. Studies in the Gospel of Matthew (pp. 228-247). Grand Rapids, Michigan - Cambridge, U.K.: Williams B. Eerdmans Publishing Company.

Juan Pablo II (1989). Redemptoris Custos. Exhortación Apostólica sobre la figura y la misión de San José en la vida de Cristo y de la Iglesia. Recuperado en http://www.vatican.va/content/john-paul-ii/es/apost_exhortations/ documents/hf_jp-ii_exh_15081989_redemptoris-custos.html

Juan XXIII (196I). Le Voci. Carta Apostólica sobre el fomento de la devoción a San

José. En Acta Apostolicae Sedis 53 (1961) Discorsi, messaggi, colloqui III, pp. 205-213.

Leon XIII (1889). Quamquam pluries. Carta encíclica sobre la devoción a San José. En: Acta Leonis XIII P. M., pp. 175-180. 
López González, P. (2020). José de Nazaret: Mt 1 - 2 y sus efectos en la tradición viva de la Iglesia. Excerpta e Dissertationibus in Sacra Theologia. Cuardenos doctorales, 69, 81-160.

Luz, U. (1993). El Evangelio según San Mateo (Vol. I). Biblioteca de Estudios Bíblicos 74. Salamanca: Sígueme.

Luz, U. (2001). El Evangelio de San Mateo (Vol. II). Biblioteca de Estudios Bíblicos 103. Salamanca: Sígueme.

Mancuello González, W. (2010). La importancia de la Palabra humana en el libro de los Proverbios. Senderos Bíblicos. Buenos Aires: San Pablo.

Mancho Duque, M. J. (2014). Claves de la escritura teresiana. Salamanca Revista de Estudios, 59, 103-122.

Meier, J. P. (1991). A marginal Jew. Rethingking the historical Jesus (Vol. 1). New York: ABRL.

Michelini, G. (2007). La struttura del Vangelo secondo Matteo. Bilancio e prospettive. Rivista Biblica, 55, 313-333.

O’Rourke, J. (1962). The Fulfillment Texts in Matthew. Catholic Biblical Quarterly, 24 (4), 394-403.

De Pablo Maroto, D. (2009). Lecturas y maestros de Santa Teresa. Madrid: Editorial de Espiritualidad.

Pattarumadathil, H. (2012). The True Worship of the Magi. Asian for Religious Studies 57, 21-25.

Pedroli, L. (2019). "Tu gli porrai nome”. San Giuseppe e la paternità. Anthropotes, 35, 60-61

Pellegrino, C. (2014). Maria di Nazareth, profezia vivente del regno. Un approccio narrativo a Lc 1,34. Analecta Biblica. Dissertationes 206. Roma: Gregorian \& Biblical Press.

Perrot, Ch. (2000). Los relatos de la infancia de Jesús. Mt 1-2, Lc 1-2. Cuadernos Bíblicos 18. Estella: Verbo Divino.

Pío IX (1873). Quemadmodun Deus. Urbis et Orbis Decretum. En Acta Pii IX, P. M., Tomo 5, p. 282.

Puig i Tàrrech, A. (2011). Why was Jesus not born in Nazareth? En: Hólmen, T., \&

Porter, S. E. (Eds.). Handbook for the Study of the Historical Jesus. How to study the Historical Jesus (Vol. 1) (34093436.). Leiden - Boston: Brill.

Reid, B. E. (2005). The Gospel According to Matthew. New Collegeville Bible Commentary. New Testament 1. Collegeville, MN: Liturgical Press.

Römer, T. (2014). Comment distinguer le vrai du faux prophète ? En Durand, J.-M. et al. (Eds.). (2014). Comment devient-on prophète? Actes du colloque organisé par le Collège de France, Paris, les 4-5 avril 2011. (pp. 109-120). Orbis Biblicus et Orientalis 265. Fribourg - Göttingen: Academic Press - Vandenhoeck Ruprecht.

Sacchi, A. (2018). "Un bambino è nato per noi”. La nascita di Gesù secondo Matteo e Luca. Milano: Youcanprint Autopublicación. .

San Agustin ( $\left.{ }^{7} 1979\right)$. Las Confesiones. Obras Completas (Vol. II.). Edición crítica, traducción y notas por Ángel Custodio Vega. Madrid: Biblioteca de Autores Cristianos.

San Juan de la Cruz (51993). Obras Completas. Revisión textual, introducciones y notas de J. V. Rodríguez, introducciones y notas marginales de F. Ruiz Salvador. Madrid: Editorial de Espiritualidad.

Sánchez Navarro, L. (2010). The Revealer of the Son. Narrative Function of the Father of Jesus in the Gospel of Saint Matthew. En De Santos, L., \& Grasso, S. (Eds). "Perché stessero con Lui". Scritti in onore di Klemens Stock SJ, nel suo $75^{\circ}$ compleanno. (pp. 71-87). Roma: Gregorian \& Biblical Press.

Sánchez-Reyes, S. (2014). San José de Ávila, la primera fundación. Salamanca Revista de Estudios, 59, 45-63. 


\section{San José en la Sagrada Escritura y en la espiritualidad}

Santa Teresa de Jesús ( $\left.{ }^{8} 1997\right)$. Obras Completas. Edición preparada por Tomás Álvarez. Burgos: Monte Carmelo.

Santa Teresa de Jesús ( $\left.{ }^{4} 1997\right)$. Cartas. Edición preparada por Tomás Álvarez. Burgos: Monte Carmelo.

Simoens, Y. (2002). Secondo Giovanni. Una traduzione e uninterpretazione. Bologna: EDB.

Ska, J.-L. (2015). El Pentateuco: un filón inagotable. Problemas de composición y de interpretación. Aspectos literarios y teológicos. Estudios Bíblicos 53. Estella: Verbo Divino.

Sociedades Bíblicas Unidas ( $\left.{ }^{3} 1994\right)$. La Biblia de Estudio. Dios Habla hoy. S.l.: Sociedades Bíblicas Unidas.

Stramare, T. (1983). Las congregaciones tituladas San José. Estudios Josefinos, 73, 9-23.

Stock. K. (2004). La missione nei Vangeli sinottici. Roma: Pontificio Istituto Biblico.

Tosato, A. (2001). Il matrimonio israelitico. Una teoria generale. Nova prefazione, presentazione e bibliografia. Analecta Biblica. Investigationes Scientificae in Res Biblicas, 100. Roma: Editrice Pontificio Istituto Biblico.

Urbieta, J. A. (Ed.). (1995). Biblia de Jerusalén. Nueva edición totalmente revisada y aumentada. Bilbao: Desclée de Brouwer.

Xiberta, B. M. (1964). Flores josefinas y la liturgia carmelitana antigua. Estudios Josefinos, 18, 301-319.

Ziegler, J. (Ed.). (1965). Sapientia Iesu Filii Sirach. Septuaginta 12 (2). Göttingen: Vandenhoeck \& Ruprecht. 